\title{
Problem of Foundationalism as a Theory of Epistemic Justification
}

\author{
Emenike Maureen Ifeyinwa \\ Department Of General Studies Faculty of Humanities \& Social Sciences Federal University Oye Ekiti
}

\begin{abstract}
As the title indicates, this paper is intended to provide an account of the foundationalist's theory of justification of infallible basic beliefs. It is surely fair to suggest that for literally thousands of years, the foundationalist's thesis was taken to be almost trivially true. What this paper sets out to do is to identify what actually constitutes the core of the foundationalists' theory, the problem with the foundationalists claim and the attack on foudationalism.

According to the foundationalist's claim, for all our beliefs to be justified they must consist of basic beliefs. These basic beliefs must be infallible, incorrigible and self justifying. Foudationalism over time have been quoted to be one of the most popular theories of justification of claims to knowledge. This paper is intended to critically evaluate this claim of the foundationalists and to be able to see how certain beliefs can be basic and self justifying and yet will not fall to subjectivity considering the fact that the basic belief is dependent on sense perception that can fall to subjectivism.
\end{abstract}

Keynote: Foudationalism, Epistemic justification, Infallible, Inferential, Basic beliefs, Incorrigible, Static.

\section{What is Foundationalism?}

Foundationalism is a theory of justification of our claims to knowledge. This position is held by some theorists of epistemic justification that all our beliefs are made up of two kinds:

Those beliefs which need support from others and need not to support themselves, that is; basic beliefs that are self justifying and non basic beliefs that need to be justified by their inferential relationship to the basic beliefs. The foundationalists went a step further to make distinctions of these beliefs and that these beliefs are divided into two groups; those that are infallible and self evident and those that are inferential.

Foundationalism as a theory of justification posits that some beliefs are incorrigible and infallible and as such does not need to be justified. Such beliefs are said to be self evident or derived by intuition ${ }^{1}$.

According to the foundationalists, all justifications of our knowledge is ultimately traceable to the foundations of basic beliefs. Every belief must have a basic foundation upon which we can derive other forms of epistemic beliefs. Any non-basic belief can only be justified if it is related to the non-basic ones. Foundationalism is a very popular theory of justification. It is of the position that all beliefs are of two kinds.

According to Dr. K.A. Owolabi, 'Foundationalism is a theory of justification that claims that a belief is justified if it is derived from some basic beliefs called foundations". ${ }^{2}$

\section{Origin of Foundationalism}

Foundationalism as a theory of justification came about as a result of the attempt of theorists of knowledge's endeavour to reduce the scepticisms attached on the truth and nature of knowledge ${ }^{3}$

Rene Descartes is taken to be one of the earlier profounder of foudationalism. He wanted to identify foundational knowledge with infallible beliefs because he wanted to build knowledge on appropriate and secure foundations. Descartes in his quest to explain his existence beyond doubt introduced foundational basic beliefs by affirming the need for the discarding of all other knowledge especially those of our senses until one gets to a solid base upon which he can build other forms of epistemic beliefs.

\section{Features of Foundationalism}

- The foundationalists claim that all justification is ultimately traceable to the foundation of justification. to the foundationalists, a particular knowledge claims can only be justified on the basis of its relationship with a basic belief.

- The foundationalists also hold the belief that, for any belief that does not belong to the set of basic belief to be justified they must be connected to those beliefs inferentially.

- The foundationalists are of the opinion that our beliefs are structural which is; foundational and super structured; between basic and non-basic beliefs. For the foundationalists our beliefs are infallible and self evident. 
- One obvious feature of foundationalism is a structural one. According to the foundationalists, all justification is ultimately traceable to the foundations of justification. Therefore, there cannot be any justified belief that is not linked to these foundations because it is the justified beliefs that form the structure of true knowledge.

- The fundamental attributes of foundationalism is that it consists of basic beliefs which are foundations of justification of truths and these beliefs are infallible, incorrigible and reliable.

- Foundationalism is static in the sense that what constitutes basic belief remains constant and unchanging irrespective of other perceived knowledge.

\section{Variances of Foudationalism.}

\subsection{Classical Foudationalism.}

The earliest form of foundationalism was classical foundationalism. Theorists of classical foudationalism posits that our basic beliefs are beliefs which are concerned with the nature of our sensory state, that is; our own immediate experience as it appears to us. They must be such beliefs that are able to stand on their own without support from others while other beliefs need support and must get it from immediate sensory states.

What this implies is that all our knowledge is derived from our sense experiences. According to the theorist of classical foundationalism, our beliefs can only be justified if it is self evident and an immediate experience. Therefore, our belief about our sensory state can be justified because they are infallible.

The position of the classical foundationalists is that any belief can either be justified by their relationship to the basic ones. The classical foundationalist holds that our basic beliefs are infallible because non-inferentially justified beliefs cannot be mistaken. The classical foundationalist believes that his sensory state is infallible.

\subsection{Cartesian Foudationalism}

The Cartesian foundationalism is a very popular theory of foundationalism. This view holds that there is need for the deconstruction of epistemic superstructures, that is, every epistemic claim should be broken down until one gets to a solid base upon which one can build other forms of epistemic beliefs. What one can call Descartes basic belief is his claim of 'cogito ergo sum', "I think therefore I am" while other beliefs which are derived inferentially from it are the non-basic beliefs. Descartes conceives beliefs as a superstructure with the basic beliefs serving as the foundation, while non-basic beliefs represent the structure itself. Descartes holds that those propositions which are directly evident for a person S have to do in some was with S's mental states- his thoughts, beliefs, feelings, perpetual experiences and others. The Cartesian foundationalists hold that basic propulsions report private psychological states.

\subsection{Chisholm's Foudationalism}

In Chisholm's Foudationalism, he holds that the basic or 'directly evident' propositions which serve as the foundation for knowledge can confer evidence upon non-basic or 'indirectly evident' propositions. He posits that a directly evident proposition is one which is evident without any other proposition serving to justify or confer evidence upon it. For Chisholm, indirectly evident propositions then are those which have epistemic status as evident propositions conferred upon them by some other proposition or propositions. Those propositions that are directly evident for a person ' $S$ ' have to do in some way with ' $S$ 's mental states-his thoughts, beliefs, feelings, perceptual experiences and others, thus the indirectly evident proposition are among those we know. Chisholm calls such directly evident propositions 'self presenting'

Chisholm's Foundational theory of knowledge is one which claims that certain types of beliefs provide the basis for our system of beliefs in the sense that they furnish the soles empirical evidence for the rest of our beliefs. He calls these foundational beliefs 'directly evident' and called the non-foundational knowledge claims based upon them 'directly evident'.

\subsection{Moorean Foudationalism}

The Moorean Foundationalists holds that basic propositions concern common sense beliefs and that these beliefs are universally and compulsively held. The Moorean foundationalists claim that basic propositions are about really observable public facts. They insists that a normal human being cannot help holding these beliefs, even if he holds beliefs simultaneously which are inconsistent with common sense belief.

Mooreans claim that these beliefs are basic because they are presupposed by all other beliefs. Their claim is that basic prepositions expressing common sense beliefs concern the unavoidable features presented by the human perception of the world and that these perceptions can be refined and expanded by theories and instruments. But the themes must be tested and the instrument must be calibrated by reference to common sense beliefs. 


\section{Problems of foundationalism as a theory of epistemic justification}

The major problem of foundationalism is the claim that some beliefs are self evident and infallible. What the foundationalist is trying to say here is that those beliefs that are infallible and self-evident are possible to exist without being justified.

One problematic aspect of foundationalism is the failure of foundationalism as a theory of justification to defend some of its basic positions. The issues of self-justification, infallibility and incorrigibility as qualities of basic beliefs cannot be defended. Some critics of foundationalism are of the opinion that basic beliefs cannot attain these superlative qualities because we cannot be talking about infallible, incorrigible and self-evident beliefs with fallible beings in-control of those belief bearing in mind the effects of sense perception, environment, culture and the psychology of individuals at certain times in interpretation and perception of the things that are presented to them. This guides against the objectivity of the theory of knowledge which holds that knowledge is subject to interrogation.

Another problem of foundationalism is the problem of infinite regression. The belief that these set of propositions can only be justified by these basic beliefs is static. The question here therefore is what actually constitutes these basic beliefs?

The foundationalist also conceives beliefs as hierarchically arranged. One would then ask, from where did the foundationalism conceive these basic beliefs and the criteria for the assertion? Is the issue of selfjustification, infallibility, and incorrigibility of the beliefs enough criteria for the justification of truth? It has been proved that these qualities ascribed to the basic belief cannot be defended.

How does the foundationalist account for the basic beliefs serving as a justification for our beliefs? There have been numerous arguments about the foundationalism, non-inferential nature of belief. Because if what justifies a belief is non-inferential and as such inaccessible, how can we then justify such non-inferential basic belief, does this mean that every basic belief is true and justified regardless of its source?

Lawrence Bonjour raised an objection to the claims of the foundationalist that our beliefs are non inferential. He objects that,

A feature of a belief or epistemic situation that makes a belief non-inferentially justified must be a feature to which we have actual or potential access. What this implies is that non-inferential beliefs are not accessible; therefore how can they be the foundations of our basic beliefs? Another problem of foundationalism is the problem of our minds. The knowledge we have of ourselves are secured while those held by others outside of ourselves we cannot really account for, how then do we lay claims on such knowledge as being justified when they are not accessible by others?

The argument from error can be used to show that we know of cases where others have successfully concealed their state of mind or pretend to be in a state of mind other than their own ${ }^{5}$.

How is one's empirical beliefs justified? Reflection on these questions has led some theorist to what has come to be called the 'Regress Problem'. Thus it has been held that because the justification of any belief requires appeal to additional beliefs and the justification of these beliefs appeal to still to further beliefs and so on.

According to Lawrence Bonjour in Jonathan Dancy's Problems of Epistemic Justification, he holds that attempts at justification can never be carried through others, less pessimistic; have pictured justificatory claims as looping back on themselves. Here belief is thought to be justified not by being fastened to some secured mooring, but by its contribution to a self contained edifice comprised of other related beliefs. What is less obvious, however, it is the extent to which they provide a satisfactory portrayal of the structure of epistemic justification. One is sometimes encouraged to accept the picture on the grounds that it is the only one seriously in the running. An endless chain of justification seems both unworkable and unhelpful: a belief moored on an infinite tether is not moored at all. On the other hand, the prospects of locating foundational beliefs capable of generating warrant without themselves requiring the support of other beliefs seem dim indeed.

Recently, Lawrence Bonjour has argued that these prospects are not simply dim, but that they are altogether unimaginable. The possibility of epistemic justification depends on ones capacity to connect beliefs to other justified beliefs. When such linkage is absent, so is justification. The notion that some beliefs might be epistemically basic or foundational is according to Bonjour, 'extremely Paradoxical', according to Bonjour, Foundationalist do not deny that inferential justification occurs, only that all justification is inferential. There are, it is thought, certain basic beliefs which are justified immediately. A belief $B$ may be regarded as a basic just in case it is justified solely in virtue of its possession of a certain property $Q$, whose property does not include essentially any further justified belief. But now it begins to look extremely doubtful that there could be basic beliefs.

Foundationalism as a theory of knowledge justification is static. The foundationalists believe that what constitutes as a basis of knowledge cannot change. With these one can infer that the theory of foundationalism can run into absolutism. 


\section{Attacks on Foudationalism}

\subsection{Will's Criticism}

Will's objection to the position of foundationalism is focussed on the claims of independence and incorrigibility, which is understood as the impossibility of justifies rejection or revision. As a result of this, one's supposition that one's sensation is of a certain character is liable both to error and revision.

\subsection{Lehrer's Criticism}

Lehrer attacks the foundationalist's theory both on the basic and non-basic level. As for the former, he considers whether the beliefs we need for our foundations are self justified after arguing that independent information is required for justification.

\subsection{Fallibilistic Attack}

The Fallibilistic attack on foundationalism is the denial of the possibility of direct, non-inferential knowledge. Because such knowledge is supposed to be the result of pure observation and observation is pure if it involves no interpretation. This is because in the absence of interpretation the possibility of error is removed. Therefore, if there is a direct knowledge then foundationalism will stand with their incorrigible basic knowledge. But there is no direct knowledge because there is no pure observation. It then means that what fallibilism in foundationalism implies is that basic knowledge is subjective. But we all know that true knowledge according to Gettier's Justified True Belief (JTB) in both subjective and objective and that JTB is objective. Subjective Knowledge is the psychological state of a person and it is fallible. Objective knowledge is the benefit gained from human inquires. And it would exist even if all people died because it is independent of man.

\section{Evaluation and conclusion}

Foundationalism as a theory of justification has tried to hold the position that our personally held beliefs should serve as foundations for all our knowledge claims. In as much as any claim to knowledge must be anchored on a source or on a foundation which are dependent on an individual's sense perception. For me therefore, it suggests that our claims to knowledge would be subjective and relative. For instance what holds to be true for A might not be true for B, in so far as A and B hold individual basic beliefs. Like John Locke holds that:

A person is directly aware only of the nature of his or her own ideas; everything else is known indirectly if at all.

We know the nature of our own sensory states perhaps, but how can we build from there to gain knowledge of a past, a future, or the sensory state of others which in itself should also constitute knowledge.

\section{References}

[1]. Jonathan Dancy. An Introduction to Cotemporary Epistemology. Oxford, Basic Blackwell, Inc, 1985 , pp 55-61.

[2]. Kolawole A.Owolabi. Issues \& Problems in Philosophy Nig. Grovacs (Network) 2000, pp 6-10.

[3]. Roderick Chisholm. Theory of Knowledge. New Jersey, Prentice-Hall, Inc, 1977, pp.11.

[4]. Jonathan Dancy. Op. Cit. p.57.

[5]. Ibid.

[6]. Rene Descartes. The Philosophical Works of Descartes, vol 2, edited and translated by E.S Haldane and G.R.T Ross, Cambridge, Cambridge University Press. 1955,

[7]. Bonjour, Lawrence. Externalist Theories of Empirical Knowledge in French et al, 1980, PP 53-73.

[8]. Richard Fumerton. Stanford Encyclopaedia of Philosophy. USA, Stanford University Press 2005.

[9]. Timm Triplett. Chisholm's Foudationalism. Boston D. Reidel Publishing Co. 1980.

[10]. John Kekes. Recent Trends and Future Prospects in Epistemology in Meta Philosophy. Vol. 8, No 52 and 3 April/July 1977 , pp.87.

[11]. John Locke. An Essay Concerning Human Understanding, edited by J. Yolton. London, Everyman's Liberty, Dutton Press. 1960. 